\title{
PENERAPAN SISTEM ACTIVITY BASED COSTING SEBAGAI DASAR PENETAPAN TARIF LEMBAGA PENDIDIKAN PADA THE BRIDGE MANADO
}

\author{
Andika Saputra Popang ${ }^{1}$, Winston Pontoh ${ }^{2,}$ Sintje Rondonuwu ${ }^{3}$ \\ ${ }^{1,2,3}$ Fakultas Ekonomi dan Bisnis, Jurusan Akuntansi, Universitas Sam Ratulangi, Jl. Kampus Bahu, Manado, \\ 95115, Indonesia
}

E-mail : popang_andika@yahoo.com

\begin{abstract}
Activity Based Costing system (ABC) is an accounting system that calculates cost based on activities in a company and charge the cost to the product based on cost driver. Therefore, ABC system removes cost distortion that occurs on conventional accounting cost system, and is able to produce a more accurate cost value. This research aims to determine the difference between $A B C$ and conventional cost system in determining the cost of goods sold in an educational institution at PT. Anugerah Bina Bersama Abadi. The results shows that cost of goods sold using the ABC system when compared to the conventional accounting cost on the English and TOEFL Class are lower, with a difference of Rp.21.746,6 and Rp.159.001,15 respectively, while higher on the Community Class with a difference of Rp.153.969,74.Rp.153.969,74.
\end{abstract}

Keywords: Activity based costing, cost of goods sold

\section{PENDAHULUAN}

Pendidikan sangatlah penting bagi keberlangsungan hidup masyarakat. Pendidikan dapat menentukan seseorang untuk mendapatkan pekerjaan yang ia inginkan atau tidak. Di era modern ini, semakin tinggi tingkat pendidikan seseorang, atau semakin banyak ilmu yang seseorang ketahui, maka semakin tinggi peluang seseorang untuk mendapatkan pekerjaan yang berpenghasilan tinggi. Maka daripada itu, masyarakat berusaha semaksimal mungkin untuk mendapatkan ilmu sebanyak-banyakanya.

Salah satu usaha jasa dibidang pendidikan yang marak ditemukan adalah lembaga pendidikan bahasa Inggris. Dengan lebih banyaknya orang asing yang berkunjung ke Indonesia, dan juga Pemerintah Indonesia yang sudah membuka peluang bagi warga asing untuk bekerja di Indonesia dalam komunitas Masyarakat Ekonomi Asean (MEA), masyarakat Indonesia menilai bahwa bahasa Inggris sangat penting untuk dikuasai agar dapat bersaing di era global. Banyaknya perusahaan jasa pendidikan bahasa Inggris di Indonesia membuktikan bahwa banyaknya permintaan pasar akan jasa tersebut.

Banyaknya usaha dibidang jasa pendidikan bahasa Inggris pada kalangan masyarakat, menuntut manajemen untuk menemukan cara-cara ampuh yang dapat memenangkan persaingan dengan lembaga pendidikan lainnya. Salah satu cara tersebut adalah untuk menentukan tarif jasa yang lebih rendah dari lembaga pendidikan lainnya, dan hal tersebut dapat dilakukan dengan cara menghitung akurat biaya-biaya yang dikeluarkan, agar dapat meningkatkan laba perusahaan.

Untuk mendapatkan laba yang optimal, perusahaan harus mengetahui biaya-biaya yang meliputi suatu produk. Perusahaan-perusahaan biasanya menggunakan akuntansi biaya konvensional untuk mengetahui biaya dari suatu produk. Namun sistem akuntansi biaya konvensional hanya relevan bila perusahaan hanya menjual satu produk saja. Jika perusahaan sudah memiliki dua atau lebih produk, hampir semua produk memiliki faktor - faktor biaya yang berbeda dalam memproduksi produk tersebut. Maka dari itu dikembangkanlah sistem 
activity based costing (ABC) sebagai sebuah sistem yang dapat memberikan informasi akuntansi biaya yang akurat. Sistem ini membebankan biaya - biaya produksi sesuai dengan aktivitas yang digunakan suatu produk.

Salah satu perusahaan yang memberikan jasa pendidikan bahasa Inggris adalah The Bridge Manado. The Bridge merupakan suatu lembaga pendidikan yang memberikan jasa pendidikan bahasa Inggris bagi para konsumennya. Lembaga pendidikan ini memiliki berbagai jenis pelayanan jasa pendidikan bahasa Inggris, dari pendidikan bahasa Inggris dasar, sampai pemberian jasa tes TOEFL (Test of English as a Foreign Language).

Untuk menghitung harga pokok jasa pendidikan, The Bridge masih menggunakan sistem akuntansi biaya konvensional. The Bridge juga belum mengetahui dan menerapkan sistem ABC. Sistem akuntansi biaya konvensional dapat mengakibatkan distorsi biaya, terutama pada The Bridge yang mempunyai berbagai aktivitas biaya yang harus ditelusuri ke dalam tiap jasa yang dihasilkannya. Hal ini dapat menrugikan manajemen The Bridge dalam hal pengambilan keputusan, terutama dalam hal penetapan tarif jasa pendidikan, karena manajemen mengambil keputusan berdasarkan informasi biaya yang terdistorsi. Penerapan sistem $\mathrm{ABC}$ dapat memberikan pengukuran biaya kepada setiap aktivitas dengan lebih akurat dan terperinci ke dalam masing - masing produk atau jasa perusahaan, sehingga biaya-biaya tersebut dapat lebih mudah ditelusuri. Sehubungan dengan penjelasan tersebut, penulis terdorong untuk melakukan penelitian mengenai penerapan sistem $\mathrm{ABC}$ sebagai dasar penetapan tarif jasa pendidikan pada The Bridge.

\section{TINJAUAN PUSTAKA}

\subsection{Biaya}

Biaya didefinisikan sebagai waktu dan sumber daya yang dibutuhkan dan menurut konvensi diukur dengan satuan mata uang (Lestari dan Permana, 2017:14). Biaya merupakan konsep dasar yang terpenting dalam akuntansi manajemen. Perusahaan yang bersifat for-profit yang tujuannya adalah untuk menghasilkan keuntungan sebesar-besarnya haruslah dengan saksama mengetahui biaya-biaya yang ada di dalam sebuah perusahaan. Bahkan organisasi non-profitpun penting untuk mengetahui biaya-biaya yang ada agar dapat secara efisien menggunakan aktiva mereka untuk tujuan organisasi.

\subsection{Akuntansi Biaya}

Akuntansi biaya adalah suatu bidang akuntansi yang diperuntukkan bagi proses pelacakan, pencatatan dan pelaporan keuangan maupun non keuangan mengenai penggunaan biaya atau sumber daya dalam organisasi (Horngren, et al., 2015:4).

\subsubsection{Objek Biaya}

Objek biaya menurut Bustami dan Nurlela (2013:8) adalah tempat dimana biaya atau aktivitas diakumulasikan

\subsubsection{Klasifikasi Biaya}

Pemahaman mengenai pengklasifikasian biaya dalam sebuah perusahaan sangatlah penting dalam keberhasilan merencanakan dan mengendalikan biaya perusahaan. Pada dasarnya, ada tiga klasifikasi biaya yaitu biaya tetap, biaya variable dan biaya semivariabel.

\subsubsection{Biaya Overhead Pabrik}

Menurut Lestari dan Permana (2017:70), biaya overhead adalah biaya produksi di luar biaya bahan baku langsung dan biaya tenaga kerja langsung, yang terdiri dari biaya overhead variabel dan biaya overhead tetap.

Menurut Rachmina dan Sari $(2017 ; 35)$, biaya-biaya produksi yang termasuk dalam biaya overhead pabrik juga dapat dikelompokkan berdasarkan sifatnya yaitu:

1. Biaya bahan penolong,

2. Biaya reparasi dan pemeliharaan, 
3. Biaya tenaga tidak langsung,

4. Biaya timbul karena waktu,

5. Biaya yang timbul sebagai akibat berlalunya waktu,

6. Biaya overhead lainnya yang memerlukan biaya uang tunai

\subsubsection{Penetapan Tarif Overhead}

Menurut Lestari dan Permana (2017:70), overhead umumnya dibebankan dalam bentuk tarif. Adapun tahap-tahap membuat tarif overhead adalah:

1. Pilih periode anggaran yang akan digunakan,

2. Pilih dasar alokasi pembebanan biaya ke output,

3. Tentukan biaya overhead-nya.

4. Hitung tariff biaya overhead per unit dasar alokasi dengan rumus:

Total biaya overhead (variabel atau tetap) Total jumlah dasar alokasi

\subsubsection{Harga Pokok Produksi}

Penentuan harga pokok produksi sangatlah penting dalam suatu perusahaan karena beberapa alasan berikut ini:

1. Untuk menetapkan harga jual produk.

2. Untuk pengendalian efisiensi biaya.

3. Sebagai dasar pengambilan keputusan.

4. Untuk menentukan nilai persediaan dalam neraca.

5. Sebagai dasar perencanaan laba.Harga pokok produksi menurut.

\subsubsection{Sistem Akuntansi Biaya Konvensional}

Sistem akuntansi biaya konvensional adalah sebuah sistem pembiayaan yang menyediakan informasi mengenai biaya, dimana biaya tersebut ditelusuri ke setiap produk karena setiap produk mengkonsumsi sumber daya. Biaya-biaya yang dialokasikan

\subsubsection{Sistem Activity Based Costing}

Sistem activity based costing (ABC) menurut Sujarweni (2015:122) adalah sistem akumulasi biaya dan pembebanan biaya ke produk dengan menggunakan berbagai cost driver, dilakukan dengan menelusuri biaya dari aktivitas dan setelah itu menelusuri biaya dari aktivitas ke produk.

Sedangkan menurut Salman dan Farid (2016:80), ABC adalah perhitungan biaya yang dimulai dengan penelusuran aktivitas-aktivitas dan kemudian memproduksi produk. Atau dengan kata lain, $\mathrm{ABC}$ adalah proses sistem perhitungan biaya yang berfokus pada aktivitasaktivitas untuk menghasilkan produk. Sistem ABC mengasumsikan bahwa aktivitas-aktivitas di dalam perusahaan bertanggung jawab atas timbulnya biaya dan produk menciptakan permintaan akan aktivitas itu.Sistem akuntansi biaya konvensional adalah sebuah sistem pembiayaan yang menyediakan informasi mengenai biaya, dimana biaya tersebut ditelusuri ke setiap produk karena setiap produk mengkonsumsi sumber daya.

\subsubsection{Kriteria Penerapan Sistem Activity Based Costing}

Terdapat beberapa kriteria penerapan sistem activity based costing (ABC) pada perusahaan, antara lain adalah:

1. Diversitas produk.

2. Support diversity

3. Common process

\subsubsection{Biaya Overhead Pada Sistem Activity Based Costing}

Menurut Salman dan Farid (2016:83) ada lima tahapan perhitungan biaya berdasarkan sistem ABC yaitu:

1. Mengidentifikasi dan menentukan aktivitas-aktivitas dan pool biaya aktivitas. 
2. Jika memungkinkan, biaya ditelusuri secara langsung ke aktivitas dan objek biaya.

3. Membebankan biaya ke pool biaya aktivitas.

4. Menghitung tarif aktivitas dengan menggunakan rumus:

$$
\text { Tarif per unit cost driver }=\frac{\text { Jumlah Aktivitas }}{\text { Cost Driver }}
$$

5. Membebankan biaya ke objek biaya dengan menggunakan tarif aktivitas dan ukuran-ukuran aktivtias.Ditinjau dari sudut lembaga yang memungut pajak, maka kita bisa membagi jenis pajak menjadi dua jenis yaitu (Mardiasmo,2016:8).

\subsubsection{Cost Driver}

Cost driver digunakan untuk menghitung biaya sumber dari setiap unit aktivitas, dan selanjutnya dibebankan ke produk atau jasa denga cara mengalihkan biaya setiap aktivitas yang dikonsumsi pada periode tertentu.

\subsubsection{Kelebihan dan Kelemahan Sistem Akuntansi Biaya Konvensional}

Kelebihan dari sistem akuntansi biaya konvensional adalah:

1. Mudah diterapkan

2. Mudah diaudit

Kelemahan dari sitem akuntansi biaya konvensional adalah:

1. Terdistorsinya biaya produksi

2. Berorientasi fungsional

\subsubsection{Kelebihan dan Kelemahan Sistem Activity Based Costing}

Kelebihan dari sistem activity based costing (ABC) adalah:

1. Harga tidak terdistorsi

2. Mengukur hubungan dengan pelanggan

3. Pemahaman atas biaya aktivitas

4. Membantu manajemen dalam pengambilan keputusan

5. Biaya Produk lebih akurat

Menurut Salman dan Farid (2016:96) kelemahan dari sistem ABC adalah:

1. Implementasi sistem ABC yang berbiaya mahal

2. Sistem yang kompleks

3. Ketidak familiaran akan sistem ABC

4. Data mudah disalahtafsirkan.

\subsection{Penelitian Terdahulu}

Ocky Satrya Wicaksono tahun 2014 dengan judul Penerapan Activity Based Costing Sebagai Alternatif Untuk Menghitung Tarif Sumbangan Pembinaan Pendidikan Pada SMA Institut Indonesia Semarang. Hasil penelitian menunjukkan adanya perbedaan signifikan antara perhitungan biaya menggunakan merode konvensional dan menggunakan metode $\mathrm{ABC}$ dimana adanya overcost sebesar Rp.44.707 jika menggunakan metode konvensional dibandingkan menggunakan ABC.

Ria Sandi Purwoadi tahun 2014 dengan judul Penerapan Activity Based Costing Sebegai Pendekatan Baru Untuk Menghitung Tarif Sumbangan Pembinaan Pendidikan Pada SMP Setiabudhi Semarang. Hasil penelitian ini menunjukkan adanya undercost dengan menggunakan ABC yaitu sebesar Rp.36.207 dibandingkan dengan menggunakan metode konvensional. 


\section{METODE PENELITIAN}

\subsection{Jenis Penelitian}

Jenis penelitian yang digunakan adalah penelitian kualitatif dengan menggunakan pendekatan deskriptif. Penelitian ini mengeksplorasi dan memotret situasi yang akan diteliti secara luas dan mendalam, khususnya dalam bidang activity based costing pada perusahaan The Bridge Manado.

\subsection{Tempat Dan Waktu Penelitian}

Penelitian ini akan dilaksanakan pada perusahaan The Bridge Manado. Waktu penelitian direncanakan akan dimulai pada bulan Februari 2018 hingga selesai.

\subsection{Prosedur Penelitian}

Prosedur penelitian yang akan dilakukan adalah :

1. Permohonan mengadakan penelitian

2. Pengumpulan data

3. Pengolahan data

4. Pengambilan keputusan

5. Pemberian saran

\subsection{Metode Pengumpulan Data}

\subsubsection{Jenis Data}

Penelitian terbagi menjadi dua bagian yaitu sebagai berikut:

1. Data Primer

2. Data Sekunder

\subsubsection{Sumber Data}

Ada dua sumber data penelitian yang digunakan dalam penelitian ini, antara lain adalah:

1. Wawancara

2. Observasi

\subsubsection{Teknik Pengumpulan Data}

1. Teknik Wawancara

2. Teknik Dokumentasi

\subsection{Metode Analisis}

Metode analisis data yang digunakan adalah metode analisis deskriptif. analisis yang digunakan dalam penelitian ini adalah deskriptif.

\section{HASIL ANALISIS DAN PEMBAHASAN}

\subsection{Hasil Penelitian}

Hasil wawancara dengan pimpinan, divisi keuangan dan divis administrasi The Bridge mengungkapkan bahwa The Bridge menerapkan sistem akuntansi biaya konvensional.

Berdasarkan data-data yang diberikan, The Bridge memiliki tiga kelas yaitu English Class dengan tarif kelas sebesar Rp.1.500.000, TOEFL Class dengan tarif kelas sebesar Rp.1.500.000, dan Community Class dengan tarif kelas sebesar Rp.50.000.

Data jumlah siswa berdasarkan kelas yaitu English Class sebesar 179 siswa, TOEFL Class sebesar 113 siswa, dan Community Class sebesar 371 siswa.

Pendapatan penjualan kelas The Bridge bisa dilihat pada tabel 4.1.

Tabel 4.1.

\begin{tabular}{|l|r|r|r|}
\hline \multicolumn{1}{|c|}{ Jenis Jasa } & $\begin{array}{r}\text { Jumlah Siswa } \\
\text { (1) }\end{array}$ & $\begin{array}{r}\text { Tarif Jasa (Rp.) } \\
\text { (2) }\end{array}$ & $\begin{array}{r}\text { Pendapatan Jasa (Rp.) } \\
\text { (1) x (2) }\end{array}$ \\
\hline English Class & 179 & 1.500 .000 & 268.500 .000 \\
TOEFL Class & 113 & 1.500 .000 & 169.500 .000 \\
Community Class & 371 & 50.000 & 18.550 .000 \\
\hline Jumlah & $\mathbf{6 6 3}$ & $\mathbf{2 . 5 5 0 . 0 0 0}$ & $\mathbf{4 5 6 . 5 5 0 . 0 0 0}$ \\
\hline
\end{tabular}


Biaya langsung kelas The Bridge tahun 2017 dapat dilihat pada tabel 4.2.

Tabel 4.2.

\begin{tabular}{|c|r|r|r|}
\hline $\begin{array}{c}\text { Elemen Biaya } \\
\text { Langsung }\end{array}$ & English Class & TOEFL Class & $\begin{array}{c}\text { Community } \\
\text { Class }\end{array}$ \\
\hline Tenaga Kerja & 42.000 .000 & 42.000 .000 & 0 \\
Biaya Buku & 8.055 .000 & 3.390 .000 & 0 \\
\hline Total Biaya Langsung & $\mathbf{5 0 . 0 5 5 . 0 0 0}$ & $\mathbf{4 5 . 3 9 0 . 0 0 0}$ & $\mathbf{0}$ \\
\hline
\end{tabular}

Biaya tidak langsung The Bridge tahun 2017 dapat dilihat pada tabel 4.3.

Tabel 4.3.

\begin{tabular}{|c|c|}
\hline Elemen Biaya Tidak Langsung & Biaya (Rp.) \\
\hline Biaya gedung & 75.000 .000 \\
\hline Karyawan & 124.800 .000 \\
\hline Listrik & 13.969 .733 \\
\hline Air & 1.011 .673 \\
\hline Telepon dan internet & 7.711 .500 \\
\hline Peralatan & 5.560 .000 \\
\hline Pemeliharaan & 2.779.000 \\
\hline Penyusutan & 1.675 .000 \\
\hline Pemasaran & 3.000 .000 \\
\hline $\begin{array}{c}\text { Total Biaya Tidak Langsung } \\
\end{array}$ & 235.506 .906 \\
\hline
\end{tabular}

\subsection{Pembahasan}

\subsubsection{Perhitungan Harga Pokok Kelas Menggunakan Sistem Biaya Konvensional}

Berdasarkan data-data yang diperoleh dari hasil penelitian di The Bridge, maka harga pokok jasa untuk tiap jenis kelas dapat dihitung berdasarkan metode konvensional sebagai berikut:

1. Menghitung pendapatan dari tiap kelas The Bridge pada periode tahun 2017 yang bisa dilihat pada tabel 4.1.

2. Persentase pendapatan dari tiap kelas terhadap pendapatan dari penjualan secara keseluruhan selam tahun 2017 harus diketahui, yang dapa dilihat pada tabel 4.4.

Tabel 4.4.

\begin{tabular}{|l|c|c|c|}
\hline \multicolumn{1}{|c|}{ Jenis Jasa } & $\begin{array}{c}\text { Pendapatan } \\
\text { Jasa (Rp.) }\end{array}$ & $\begin{array}{c}\text { Total Pendapatan } \\
\text { Jasa (Rp.) } \\
(\mathbf{1})\end{array}$ & $\begin{array}{c}\text { Persentase } \\
\text { Pendapatan } \\
((\mathbf{1}):(\mathbf{2})) \times \mathbf{1 0 0 \%}\end{array}$ \\
\hline English Class & 268.500 .000 & & $58,81 \%$ \\
TOEFL Class & 169.500 .000 & 456.550 .000 & $37,13 \%$ \\
Community Class & 18.550 .000 & & $4,06 \%$ \\
\hline Jumlah & $\mathbf{4 5 6 . 5 5 0 . 0 0 0}$ & $\mathbf{4 5 6 . 5 5 0 . 0 0 0}$ & $\mathbf{1 0 0 \%}$ \\
\hline
\end{tabular}

3. Setelah persentase pendapatan tiap kelas didapat, total biaya tidak langsung The Bridge dikalikan dengan persentase pendapatan tiap kelas untuk mendapatkan total nilai biaya tidak langsung untuk masing-masing kelas. Total nilai tersebut ditambahkan dengan total biaya langsung masing-masing kelas, dibahagi dengan jumlah siswa tiap kelas pada akhirnya akan mendapatkan nilai harga pokok kelas The Bridge yang bisa dilihat pada tabel 4.5. 
Tabel 4.5.

\begin{tabular}{|l|c|c|c|}
\hline \multicolumn{1}{|c|}{ Elemen Biaya } & English Class & TOEFL Class & $\begin{array}{c}\text { Community } \\
\text { Class }\end{array}$ \\
\hline Biaya Langsung & 50.055 .000 & 45.390 .000 & 0 \\
\hline \multicolumn{4}{|c|}{ Biaya Tidak Langsung } \\
\hline $58,81 \%$ x 235.506.906 & $138.501 .611,42$ & & \\
\hline $37,13 \%$ x 235.506.906 & & $87.443 .714,20$ & \\
\hline $4,06 \%$ x 235.506.906 & & & $9.561 .580,38$ \\
\hline Total Harga Pokok Kelas & $188.556 .611,42$ & $132.833 .714,20$ & $9.561 .580,38$ \\
\hline Jumlah Siswa & 179 & 113 & 371 \\
\hline Harga Pokok Kelas & $\mathbf{1 . 0 5 3 . 3 8 8 , 8 9}$ & $\mathbf{1 . 1 7 5 . 5 1 9 , 5 9}$ & $\mathbf{2 5 . 7 7 2 , 4 5}$ \\
\hline
\end{tabular}

\subsubsection{Perhitungan Harga Pokok Kelas Menggunakan Sistem Activity Based Costing (ABC)}

Adapun langkah-langkah yang dilakukan untuk menghitung harga pokok kelas berdasarkan sistem ABC dalam penelitian ini adalah :

1. Mengidentifikas dan mendefinisikan aktivitas yang terjadi. Aktivitas tersebut adalah aktivitas penggunaan gedung, penggajian tenaga kerja, penggunaan listrik, penggunaan air, penggunaan telepon dan internet, penggunaan perlengkapan tulis menulis, pemeliharaan peralatan, penyusutan peralatan dan pemasaran.

2. Mengidentifikasi aktivtias biaya tidak langsung dan level aktivitasnya.

Adapun level aktivitas bisa dilihat pada tabel 4.6.

Tabel 4.6.

\begin{tabular}{|c|c|c|}
\hline No. & Aktivitas & Level Aktivitas \\
\hline 1. & Aktivitas Penggunaan Gedung & Fasilitas \\
2. & Aktivitas Penggajian Tenaga Kerja & Fasilitas \\
3. & Aktivitas Penggunaan Listrik & Fasilitas \\
4. & Aktivitas Penggunaan Air & Fasilitas \\
5. & Aktivitas Penggunaan Telepon dan Internet & Fasilitas \\
6. & Aktivitas Penggunaan Perlengkapan Tulis Menulis & Unit \\
7. & Aktivitas Pemeliharaan Peralatan & Fasilitas \\
8. & Aktivitas Penyusutan Peralatan & Fasilitas \\
9. & Aktivitas Pemasaran & Fasilitas \\
\hline
\end{tabular}

3. Mengidentifikasi cost driver.

Adapun cost driver dan cost pool bisa dilihat pada tabel 4.7.

Tabel 4.7.

\begin{tabular}{|l|c|}
\hline \multicolumn{1}{|c|}{ Cost Pool } & Cost Driver \\
\hline Unit Level Activity: & \\
Pool I & Jumlah Siswa \\
Aktivitas Penggunaan Perlengkapan Tulis Menulis & \\
\hline Facility Level Activity: & \\
Pool II & Total Kapasitas Siswa \\
Aktivitas Penggunaan Gedung & Total Kapasitas Siswa \\
Aktivitas Pemeliharaan Peralatan & Total Kapasitas Siswa \\
Aktivitas Penyusutan Peralatan & Total Kapasitas Siswa \\
Aktivitas Pemasaran & \\
Pool III & Jumlah Siswa \\
Aktivitas Penggunaan Listrik & Jumlah Siswa \\
Aktivitas Penggunaan Air & Jumlah Siswa \\
Aktivitas Penggunaan Telepon dan Internet & \\
Pool IV & Jumlah Jam Kerja \\
Aktivitas Penggajian Tenaga Kerja & \\
\hline
\end{tabular}


4. Menentukan tarif per unit cost driver

Tarif per unit cost driver dapat dihitung dengan rumus sebagai berikut:

$$
\text { Tarif per unit cost driver }=\underline{\text { Jumlah Aktivitas }}
$$

Cost Driver

Penentuan tarif per unit dapat dilihat pada tabel 4.8.

Tabel 4.8.

\begin{tabular}{|c|c|c|c|c|}
\hline No. & Elemen Biaya & $\begin{array}{c}\text { Jumlah Biaya } \\
\text { (Rp.) } \\
\text { (1) }\end{array}$ & $\begin{array}{c}\text { Cost Driver } \\
\text { (2) } \\
\end{array}$ & $\begin{array}{l}\text { Tarif/Unit } \\
\text { (Rp.) } \\
(1):(2)\end{array}$ \\
\hline 1. & $\begin{array}{c}\text { Unit-level activity cost } \\
\text { Pool I } \\
\text { Biaya Peralatan } \\
\text { Total }\end{array}$ & $\begin{array}{l}5.560 .000 \\
\mathbf{5 . 5 6 0 . 0 0 0}\end{array}$ & $\begin{array}{l}663 \\
663\end{array}$ & $\begin{array}{l}8.386,12 \\
\mathbf{8 . 3 8 6 , 1 2}\end{array}$ \\
\hline 2. & $\begin{array}{c}\text { Facility-level activity cost } \\
\text { Pool II } \\
\text { Biaya Gedung } \\
\text { Biaya Pemeliharaan } \\
\text { Biaya Penyusutan } \\
\text { Biaya Pemasaran } \\
\text { Total } \\
\\
\text { Pool III } \\
\text { Biaya Listrik } \\
\text { Biaya Air } \\
\text { Biaya Telepon dan Internet } \\
\text { Total } \\
\text { Pool IV } \\
\text { Biaya Tenaga Kerja } \\
\text { Total }\end{array}$ & $\begin{array}{r}13.969 .733 \\
1.011 .673 \\
7.711 .500 \\
\\
\mathbf{2 2 . 6 9 2 . 9 0 6} \\
124.800 .000 \\
\mathbf{1 2 4 . 8 0 0 . 0 0 0}\end{array}$ & $\begin{array}{l}1.080 \\
1.080 \\
1.080 \\
1.080 \\
\mathbf{1 . 0 8 0}\end{array}$ & $\begin{array}{r}69.444,44 \\
2.573,15 \\
1.550,92 \\
2.777,78 \\
\mathbf{7 6 . 3 4 6 , 3 0}\end{array}$ \\
\hline
\end{tabular}

5. Membebankan biaya overhead ke masing-masing jasa.

i. Pertama-tama harus mengalokasikan cost driver yang bisa dilihat pada tabel 4.9.

Tabel 4.9.

\begin{tabular}{|c|c|r|}
\hline No. & Cost Driver & Jumlah \\
\hline 1. & Alokasi Jumlah Siswa : & 179 \\
& English Class & 113 \\
& TOEFL Class & 371 \\
\hline \multicolumn{2}{|c|}{ Community Class } & $\mathbf{6 6 3}$ \\
\hline 2. & Total & 240 \\
& Alokasi Total Kapasitas Siswa : & 240 \\
& English Class & 600 \\
\hline \multicolumn{2}{|c|}{ TOEFL Class } & $\mathbf{1 . 0 8 0}$ \\
\hline 3. & Community Class & 4.893 \\
& Total & $3.089,208$ \\
& Alokasi Waktu Jam Kerja : & 337,792 \\
& English Class & $\mathbf{8 . 3 2 0}$ \\
\hline
\end{tabular}


ii. Kedua, harus menentukan tarif cost pool yang bisa dilihat pada tabel 4.10.

Tabel 4.10.

\begin{tabular}{|c|r|c|r|}
\hline Cost Pool & $\begin{array}{r}\text { Total Cost Pool (Rp.) } \\
(\mathbf{1})\end{array}$ & $\begin{array}{c}\text { Cost Drive } \\
(\mathbf{2})\end{array}$ & $\begin{array}{c}\text { Tarif Cost Pool (Rp.) } \\
(\mathbf{1}) \mathbf{: ( 2 )}\end{array}$ \\
\hline Cost Pool I & 5.560 .000 & 663 & $\mathbf{8 . 3 8 6 , 1 2}$ \\
Cost Pool II & 82.454 .000 & 1.080 & $\mathbf{7 6 . 3 4 6 , 3 0}$ \\
Cost Pool III & 22.692 .906 & 663 & $\mathbf{3 4 . 2 2 7 , 6 1}$ \\
Cost Pool IV & 124.800 .00 & 8.320 & $\mathbf{1 5 . 0 0 0}$ \\
\hline
\end{tabular}

iii. Tahap terakhir adalah untuk membebankan biaya overhead dari tiap aktivitas ke setiap kelas dihitung dengan rumus sebagai berikut:

BOP yang dibebankan $=$ Tarif/unit Cost Driver $\mathrm{X}$ Cost Driver yang dipilih

Pembebanan overhead ke tiap kelas bisa dilihat pada tabel 4.11. sampai tabel 4.12.

Tabel 4.11.

Harga Pokok English Class

\begin{tabular}{|c|c|r|r|r|}
\hline No. & Cost Pool & Tarif Cost Pool & Cost Driver & \multicolumn{1}{c|}{ Total (Rp.) } \\
\hline 1. & Cost Pool I & $8.386,12$ & 179 & $1.501 .115,48$ \\
\hline 2. & Cost Pool II & $76.346,30$ & 240 & 18.323 .112 \\
\hline 3. & Cost Pool III & $34.227,61$ & 179 & $6.126 .742,19$ \\
\hline 4. & Cost Pool IV & 15.000 & 4.893 & 73.395 .000 \\
\hline \multicolumn{3}{|c|}{ Total Biaya Tidak Langsung } & $99.345 .969,67$ \\
\hline & Total Biaya Langsung & 50.055 .000 \\
\hline \multicolumn{3}{|c|}{ Total Biaya English Class } & $149.400 .969,67$ \\
\hline \multicolumn{3}{|c|}{ Jumlah Siswa } & 179 \\
\hline \multicolumn{3}{|c|}{ Harga Pokok English Class } \\
\hline
\end{tabular}

Tabel 4.12.

Harga Pokok TOEFL Class

\begin{tabular}{|c|c|r|r|r|}
\hline No. & Cost Pool & Tarif Cost Pool & Cost Driver & \multicolumn{1}{c|}{ Total (Rp.) } \\
\hline 1. & Cost Pool I & $8.386,12$ & 113 & $947.631,56$ \\
\hline 2. & Cost Pool II & $76.346,30$ & 240 & 18.323 .112 \\
\hline 3. & Cost Pool III & $34.227,61$ & 113 & $3.867 .719,93$ \\
\hline 4. & Cost Pool IV & 15.000 & $3.089,208$ & 46.338 .120 \\
\hline \multicolumn{3}{|c|}{ Total Biaya Tidak Langsung } & $69.476 .583,49$ \\
\hline \multicolumn{3}{|c|}{ Total Biaya Langsung } & 45.390 .000 \\
\hline \multicolumn{3}{|c|}{ Total Biaya TOEFL Class } & $114.866 .583,49$ \\
\hline \multicolumn{3}{|c|}{ Jumlah Siswa } & 113 \\
\hline \multicolumn{3}{|c|}{ Harga Pokok TOEFL Class } \\
\hline
\end{tabular}


Tabel 4.13.

Harga Pokok Community Class

\begin{tabular}{|c|c|r|r|r|}
\hline No. & Cost Pool & Tarif Cost Pool & Cost Driver & \multicolumn{1}{|c|}{ Total (Rp.) } \\
\hline 1. & Cost Pool I & $8.386,12$ & 371 & $3.111 .250,52$ \\
\hline 2. & Cost Pool II & $76.346,30$ & 600 & 45.807 .780 \\
\hline 3. & Cost Pool III & $34.227,61$ & 371 & $12.698 .443,31$ \\
\hline 4. & Cost Pool IV & 15.000 & 337,792 & 5.066 .880 \\
\hline \multicolumn{3}{|c|}{ Total Biaya Tidak Langsung } \\
\hline \\
Total Biaya Langsung & $66.684 .353,83$ \\
\hline \multicolumn{3}{|c|}{ Total Biaya Community Class } \\
\hline \multicolumn{3}{|c|}{ Jumlah Siswa } & $66.684 .353,83$ \\
\hline \multicolumn{3}{|c|}{ Harga Pokok Community Class } & 371 \\
\hline
\end{tabular}

\subsubsection{Perbandingan SIstem Akuntansi Biaya Konvensional Dengan Sistem Activity Based Costing Dalam Penetapan Tarif Kelas}

Setelah mendapatkan hasil perhitungan tarif kelas menggunakan sistem konvensional dan sistem $\mathrm{ABC}$, dapat dilihat perbedaan dalam nilai tarif pada tabel 4.14.

Tabel 4.14.

\begin{tabular}{|c|c|c|r|}
\hline Jenis Kelas & $\begin{array}{c}\text { Harga Pokok } \\
\text { Kelas Sistem } \\
\text { Konvensional } \\
(\text { Rp. })\end{array}$ & $\begin{array}{c}\text { Harga Pokok } \\
\text { Kelas Sistem } \\
\text { ABC } \\
\text { (Rp.) }\end{array}$ & \multicolumn{1}{|c|}{ Selisih } \\
\hline English Class & $1.053 .388,89$ & $834.642,29$ & $218.746,6$ \\
\hline TOEFL Class & $1.175 .519,59$ & $1.016 .518,44$ & $159.001,15$ \\
\hline Community Class & $25.772,45$ & $179.742,19$ & $(153.969,74)$ \\
\hline
\end{tabular}

5. KESIMPULAN DAN SARAN

5.1 Kesimpulan

1. Penggunaan sistem pembiayaan berdasarkan aktivitas $(\mathrm{ABC})$ dalam perhitungan harga pokok kelas pada perusahaan The Bridge akan menghasilkan harga pokok kelas yang lebih akurat dari pada sistem konvensional, karena biaya-biaya yang terjadi dibebankan pada produk aktivitas dan sumber daya yang dikonsumsikan oleh produk dan juga menggunakan dasar lebih dari satu cost driver. Oleh karena itu, biaya produk tidak terdistorsi karena biaya-biaya pendukung atau overhead dapat dialokasikan ke tiap-tiap kelas berdasarkan persentase pendapatan.

2. Hasil dari perhitungan harga pokok kelas dengan menggunakan sistem konvensional untuk English Class sebesar Rp.1.053.388,89 , TOEFL Class sebesar Rp.1.175.519,59, dan Community Class sebesar Rp.25.772,45. Sedangkan harga pokok kelas menggunakan sistem ABC pada English Class sebesar Rp.834.642,29, TOEFL Class sebesar Rp.1.016.518,44, dan Community Class sebesar Rp.179.742,19. Dari hasil sistem ABC tersebut terdapat selisih harga yang lebih rendah dibandingkan dengan sistem konvensional pada English Class yaitu sebesar Rp.218.746,6 dan juga pada kelas TOEFL Class yaitu sebesar Rp.159.001,15. Sedangkan untuk sistem ABC pada Community Class terdapat selisih harga yang lebih tinggi dibandingkan dengan metode konvensional yaitu sebesar Rp.153.969,74.

\subsection{Saran}

Saran bagi pihak The Bridge adalah untuk sebaiknya mulai mempertimbangkan menghitung tarif kelas dengan menggunakan sistem pembiayaan berdasarkan aktivitas $(\mathrm{ABC})$. Sistem ABC dapat memberikan perincian biaya yang lebih akurat terhadap 
perhitungan tarif kelas dibandingkan dengan perhitungan menggunakan metode konvensional. Agar dapat mengimplementasikan sistem ABC dengan baik, pihak manajemen harus mempunyai sistem informasi dan tenaga kerja yang memadai, yang mempunyai pengetahuan yang cukup untuk mengimplementasikan sistem ini.

\section{DAFTAR PUSTAKA}

Bustami, B., dan Nurlela. 2013. Akuntansi Biaya. Edisi 4. Mitra Wacana Media, Jakarta.

Horngren, C. T., Srikant, M. D., dan Madhav, V. R. 2015. Cost Accounting: A Managerial Emphasis, Edisi 15. Pearson Education Ltd, Essex.

Lestari, W., dan Permana, D. B. 2017. Akuntansi Biaya dalam Perspektif Manajerial. PT RajaGrafindo Persada, Depok.

Purwoadi, R. S. 2014. Penerapan Activity Based Costing Sebagai Pendekatan Baru Untuk Menghitung Tarif Sumbangan Pembinaan Pendidikan Pada SMP Setiabudhi

Semarang. Skripsi. Universitas Dian Nuswantoro, Semarang.

Rachmina, S., dan Sari, S. W. 2017. Akuntansi Manajemen, Teori dan Aplikasi. Cetakan keempat. Polimedia Publishing, Jakarta.

Sujarweni, V. W. 2015. Akuntansi Biaya, teori dan Penerapannya. Pustaka Baru, Yogyakarta.

Salman, K. R., Farid, M. 2016. Akuntansi Manajemen, Alat Pengukuran dan Pengambilan Keputusan Manajerial. Indeks, Jakarta.

Wicaksono, O. S. 2014. Penerapan Activity Based Costing Sebagai Alternatif Untuk Menghitung Tarif Sumbangan Pembinaan Pendidikan Pada SMA Institut Indonesia Semarang. Skripsi. Universitas Dian Nuswantoro, Semarang. 